\title{
Hand muscle reflexes following electrical stimulation in choreatic movement disorders
}

\author{
G DEUSCHL, C H LÜCKING, E SCHENCK \\ From Neurologische Klinik und Poliklinik der Universität Freiburg i.Br, Freiburg, Federal Republic of Germany
}

SUMMARY Thenar reflexes following electrical stimulation of the median nerve (containing proprioceptive and cutaneous afferents) and the radial superficial nerve (cutaneous afferents only) were investigated in 23 patients with manifest Huntington's disease (HD) at an early stage, in 17 clinically healthy descendants of HD-patients and in 18 patients with choreatic hyperkinesia due to various aetiologies other than HD. In $61 \%$ of the patients with early HD the long-latency reflexes (LLR) were uni- or bilaterally absent in response to both median nerve and radial superficial nerve stimulation. The remaining patients had a diminished mean amplitude and mean duration of their LLR. In contrast, offspring and patients with symptomatic chorea had preserved LLR which did not differ in amplitude or duration from normal controls. Additionally, the mean amplitude and mean duration of the Hoffmaan-reflex (HR) was found to be increased in patients with HD and their offspring but not in patients with other aetiologies. It is concluded (1) that the loss of LLR is not related to the choreatic hyperkinesia itself but to the degeneration of a hitherto poorly defined neuronal circuit in HD; (2) that among a variety of diseases presenting with chorea, the loss of LLR seems to be specific for HD; (3) that the testing of hand muscle reflexes in choreatic movement disorders is helpful for the differential diagnosis of early HD but not for the detection of gene carriers among offspring of patients with HD.

Reflexes in the thenar muscle following electrical stimulation of the median nerve at an intensity of motor threshold consist of several components. ${ }^{1-3}$ The first is the monosynaptic spinal Hoffman Reflex (HR) followed by up to three long-latency reflexes (LLR, I, II, III). ${ }^{4}$ Only the LLR II is seen in every normal subject whereas the LLR I and LLR III are usually small reflexes occurring in only $10 \%-30 \%$ of normal subjects. The LLR II is a reflex mediated by fast conducting muscle and cutaneous afferents ${ }^{3}$ and its central transmission probably occurs along a transcortical route. ${ }^{56}$ The LLR II can also be elicited by stimulation of cutaneous nerves especially of the radial superficial nerve. ${ }^{6-9}$ It has been shown that these reflexes frequently exhibit distinct abnormalities in central nervous system disorders like spasticity, ${ }^{15}$ hemiparesis, ${ }^{10}$ multiple sclerosis ${ }^{6}$ and extrapyramidal diseases. " As they may be easily tested with routine EMG laboratory equipment they represent a tool for

Address for reprint requests: Dr G Deuschl, Neurologische Klinik und Poliklinik, Universität Freiburg i.Br., Hansastr. 9, 7800 Freiburg, FRG.

Received 15 November 1988 and in revised form 20 January 1989. Accepted 31 January 1989 studying the clinical neurophysiology of these disorders. For the purpose of the present paper only the LLR II is important and it is subsequently termed LLR, as mn-LLR when elicited by median nerve stimulation or rsn-LLR when elicited by radial superficial nerve stimulation.

Compared with these electrically elicited LLR the reflexes following muscle stretch have been extensively investigated in many different muscles of the upper and lower extremities (for review see refs 12,13). It has been shown that the long-latency component of hand reflexes is frequently lacking in Huntington's disease. ${ }^{14} 15$ This has been confirmed for the flexor pollicis longus and the finger flexors. ${ }^{16}$ It is believed that this LLR is mediated along a transcortical pathway. ${ }^{12}$ Concerning HD the responsible lesion of the reflex arc is believed to be in the afferent limb of the reflex arc to the cortex. ${ }^{15}$ This is mainly based on the observation of diminished amplitudes or absence of early somatosensory evoked potentials after median nerve stimulation in these patients. ${ }^{17} 181920$

The first aim of the present study was to investigate whether the LLR following electrical stimulation of mixed and pure cutaneous afferents which strongly resemble the stretch evoked LLR in hand muscles is 
also absent in Huntington's disease. Secondly we were interested in whether clinically unaffected descendants of patients with HD have similar reflex abnormalities which could help in the presymptomatic diagnosis of HD. Our third question was whether the LLR are also absent in other diseases associated with choreatic movements or if this finding is restricted to HD.

In order to answer these questions 58 patients with HD, healthy offspring and patients suffering from various diseases associated with chorea have been investigated for their reflex pattern following electrical stimulation of the median nerve and the radial superficial nerve. Preliminary data have been published elsewhere. ${ }^{21}$

\section{Methods and patients}

The method of eliciting LLR has been described earlier. ${ }^{3611}$ Briefly, the subjects were asked to abduct the thumb against a force transducer at $10-20 \%$ of maximum force controlled by a visual display. The median nerve or the radial superficial nerve was stimulated $(3 \mathrm{~Hz})$ at the wrist with an intensity at threshold for motor fibres (for median nerve) or at $2-2.5 x$ sensory threshold (for radial superficial nerve). The thenar EMG was recorded with surface electrodes. Filtered (1$3000 \mathrm{~Hz}$ ), full-wave rectified and averaged (256 sweeps) responses were used for quantitative analysis. The onset latencies of the reflexes were measured and the amplitudes were determined as the quotient between the absolute amplitude of HR or LLR measured between the onset to the peak amplitude and the baseline amplitude (measured within the first $20 \mathrm{~ms}$ following the stimulus). This value is known to be independent of the recording conditions and of fluctuations of the applied force. ${ }^{2223}$ The duration was measured from the onset to the end of the reflexes.

Fifty eight patients were included in the present study. Twenty three patients suffered from manifest HD (13 males, 10 females). All except one had a positive family history of HD. The disease of one patient was most probably due to a new mutation which has been described elsewhere. ${ }^{24}$ Their mean age was 44.9 years. The diagnosis was confirmed for most of them by typical abnormalities of a series of different tests: CT and MRI, ${ }^{25}$ single-photon-emission-tomography with ${ }^{99 m}$ Tc-HMPAO, ${ }^{26}$ detailed neuro-psychological analysis, ${ }^{27}$ median nerve SEP, ${ }^{118}$ P $300^{28}$ and electro-oculography. ${ }^{29}{ }^{30}$ The duration of the disease varied between 0.5 and 8 years with a mean of 3.4 years. Most patients were first diagnosed at the time of the present investigation. All except three were not under medication. In two patients reflexes could be examined only in one hand. One was an amputee from an accident in early childhood and the second recently had an operation for carpal tunnel syndrome on one hand. Seventeen healthy subjects ( 10 males, 7 females) at risk for HD were also investigated. Their mean age was 39.4 years. They had normal results in all of the above mentioned tests for HD. Eighteen patients with choreatic hyperkinesia of an origin other than HD (6 males, 12 females) have been included in the present study (table 1). All the patients and especially those with tardive dyskinesia had clearcut and mostly severe choreatic hyperkinesia of the extremities. Four had unilateral and 14 had bilateral chorea. Their mean age was 56.6 (SD: 19.4) years.

The severity of choreatic movements of the patients with HD and symptomatic chorea was rated on a 5-point scale: (0) no hyperkinesia, (1) questionable hyperkinesia, (2) slight hyperkinesia (rare, but definite choreatic movements, usually pronounced in distal muscles), (3) moderate hyperkinesia (obvious choreatic movements of distal and proximal muscles, usually some disturbance of daily activities), (4) severe hyperkinesia (severe chorea, occasional and/or pronounced difficulties during skilled movements, at least on one side).

Fifty two normal subjects ( 28 males, 24 females) with a mean age of 44 years (range: $20-84$ years) served as controls. As the amplitude and duration of the reflexes depend to a certain degree on the age of the subjects, age-matched control groups were formed for each of the three populations. The subpopulations of patients (manifest HD, offspring, patients with symptomatic chorea) and their corresponding normal control groups did not differ significantly ( $t$ test) with respect to age and sex.

All the data were fed into a personal computer and statistical analysis ( $t$ test for unpaired data or conventional correlation analysis) was performed. The data of reflex amplitudes have been transformed before applying $t$ test to ascertain normal distribution.

\section{Results}

In all patients at least the Hoffmann-Reflex (HR) could be demonstrated indicating that peripheral afferents were stimulated sufficiently to produce a long-latency reflex if present.

Following median nerve stimulation six of the 23 patients with manifest HD had bilaterally and eight had unilaterally absent mn-LLR (fig ld-f). Nine

Table Clinical data of 18 patients with chorea due to various symptomatic aetiologies.

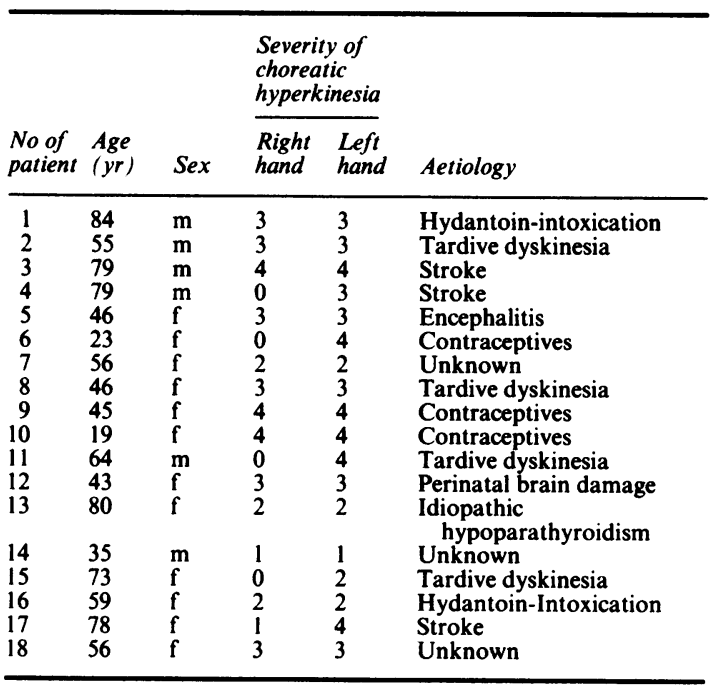




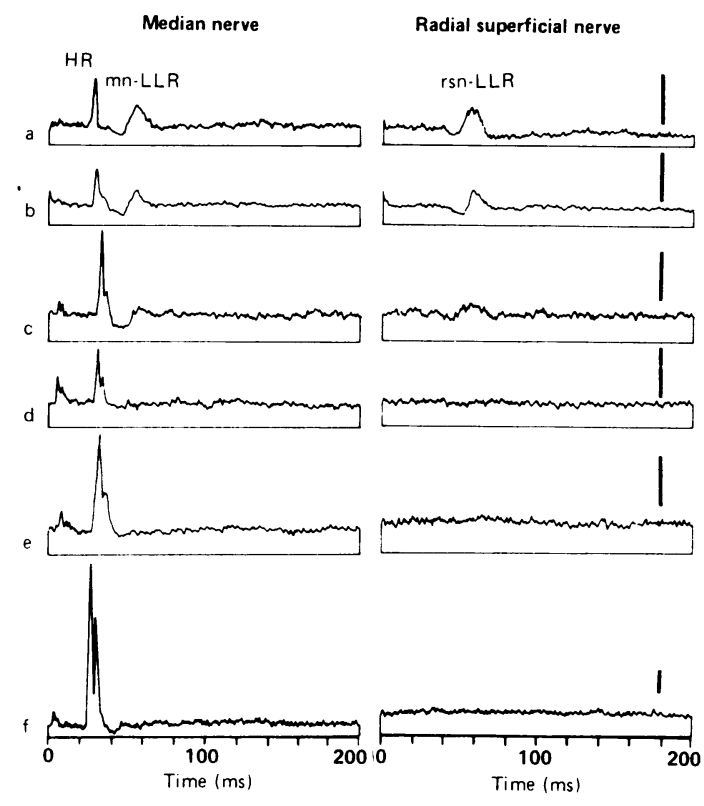

Fig 1 Hoffman-Reflex (HR) and long-latency reflex ( $L L R$ ) after stimulation of the median or radial superficial nerve. Normal reflexes in a patient with severe chorea after a stroke $(a)$ and in a subject at risk for $H D(b)$. Reflexes of patients with manifest $H D(c-f)$. A small LLR is still present in (c). The $L L R$ are absent in $(d-f)$. Large $H R$ are seen in (e) and (f). Calibration bar: $100 \mu \mathrm{V}$.

patients had small but still preserved mn-LLR (fig lc). The two patients who could only be investigated on one hand belonged to the latter group. Most of the remaining patients had rather small LLR. With the statistical methods used it is impossible to define a lower limit of the LLR-amplitudes of normal subjects. In order to determine whether the disease affects the latency, amplitude and duration of HR and LLR statistical comparison of age-matched groups of normal subjects and patients was applied. No significant differences were found concerning the latencies of the reflexes ((fig 2). Comparison of amplitude and duration of mn-LLR between normal subjects and the patients who still had preserved reflexes (fig 2) showed a highly significant decrease of both parameters in the patients (amplitude: $\mathrm{p}<0.0005$, duration: $\mathrm{p}<0.005$ ). The HR were clearly enhanced (fig If) in three patients (one bilaterally, two unilaterally) with values considerably exceeding the largest HR that we have ever seen in normal subjects. Many of the remaining patients also had unusually large HR amplitudes although they did not reach the upper normal values. Therefore, the statistical comparison of control and patient data for HR-amplitude and duration revealed highly significant levels $(\mathrm{p}<0.0005)$. Even excluding the four clearly enhanced HR, the mean value of HRamplitude was still significantly larger in the patient's group ( $\mathrm{p}<0.0005)$.

Following stimulation of the radial superficial nerve the rsn-LLR was absent bilaterally in eight patients and unilaterally in six patients (fig 1d-e). The same nine patients with preserved mn-LLR also had preserved rsn-LLR. Compared with the normal controls the mean amplitude and duration (fig 2) was diminished in the remaining rsn-LLR (amplitude: $\mathrm{p}<0.0005$, duration: $\mathrm{p}<0.0005)$. Hence $\mathrm{mn}$ - and

Normal subjects $\square$ Huntington's disease
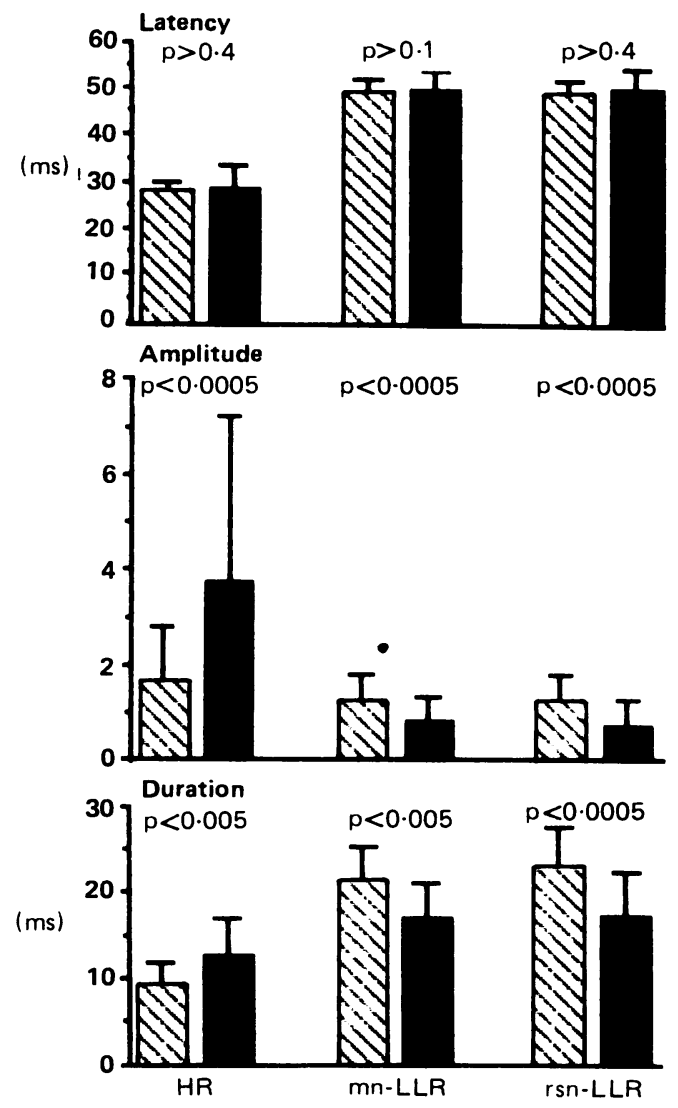

Fig 2 Statistical comparison of reflex parameters in patients with $H D$ and age-matched controls. The mean values and standard deviations of latencies, amplitudes and durations of $H R, L L R$ to median nerve stimulation ( $m n-L L R$ ) and $L L R$ to radial superficial nerve stimulation (rsn-LLR) are displayed. For HR all 44 hands were taken into account. For $m n-L L R$ and rsn-LLR the values of those 24 hands of patients who still had discernible $L L R$ were used for calculation. Unpaired t test was used. 
rsn-LLR exhibited the same alteration with reduction or abolition. One of our patients could be observed over a 4 year period. During the first admission both LLR were still normal but 4 years later they were absent (fig 3).

Among the healthy subjects at risk for HD none had absent mn- or rsn-LLR (fig 1b). Compared with the controls no significant differences of mn- or rsn-LLR were found. Only one patient had unilaterally enhanced HR. The mean HR-amplitude and HR-duration were larger for the subjects at risk than for the controls (fig 4) at a low level of significance (amplitude: $\mathrm{p}<0.05$, duration: $\mathrm{p}<0.02$ ).

For the patients with various aetiologies of their choreatic hyperkinesia neither abnormal HR nor mnor rsn-LLR were found (fig la). Taken together as a group no significant differences between the patients and normals were found for all the measured parameters (fig 5). Four of these patients could be investigated before and after successful therapy with tiaprid or valproic acid. No differences of the reflex pattern could be observed (fig 6). Statistical analysis was not possible for such a small population.

Clinical rating of the severity of the hyperkinesia was performed according to a 5-point scale (0-4, see Methods). The mean value for the patients with HD was $2 \cdot 2$, SD 0.86 and for patients with other symptomatic aetiologies was $2 \cdot 8, \mathrm{SD} 1 \cdot 05$. If the decrease of LLR is related to the severity of the choreatic hyperkinesia this should become obvious by statistical tests. However, no significant correlation between either amplitude or duration of LLR and severity of chorea was found in the case of HD $(p>0.3)$ and other aetiologies $(\mathrm{p}>0 \cdot 3)$.

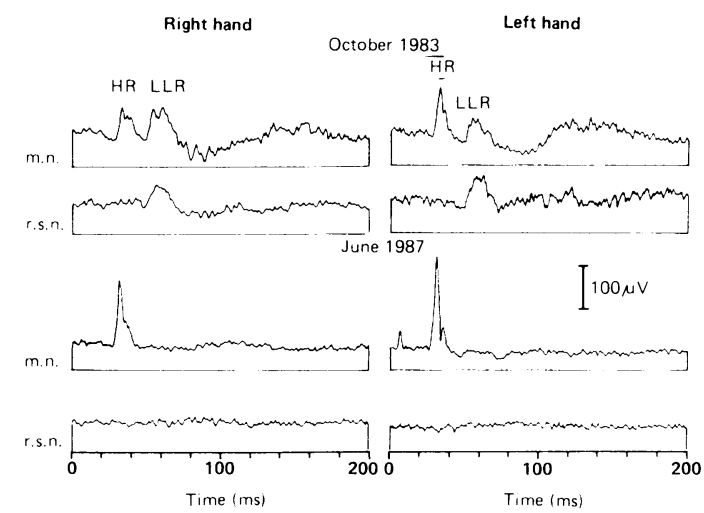

Fig 3 Reflex patterns of a patient with $H D$ recorded at different times. Both hands had normal LLR in 1983 whereas they were absent four years later. The HR of the second recording was larger. The reflex patterns following median nerve ( $\mathrm{mn}$ ) and radial superficial nerve ( $r \mathrm{sn}$ ) stimulation are shown.

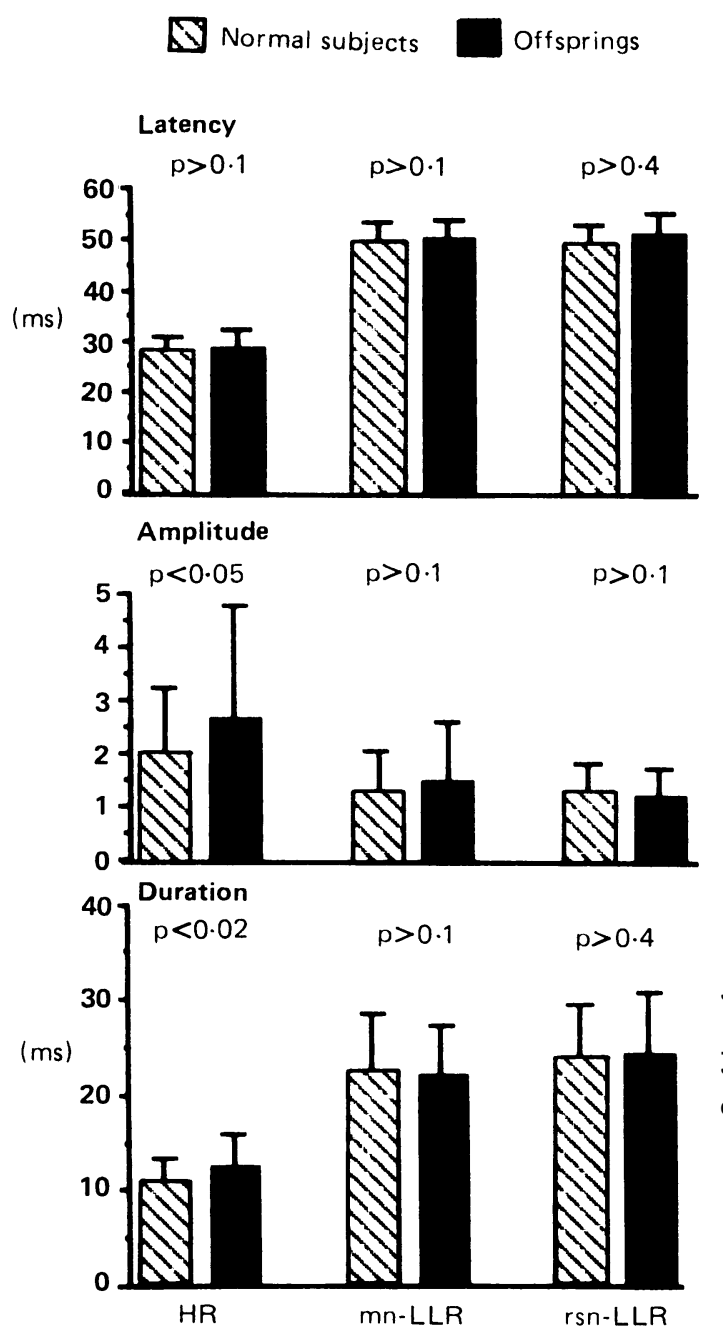

Fig 4 Statistical comparison of reflex parameters of healthy subjects at risk for HD (34 hands) and age-matched controls (unpaired $t$-test). No differences were found in case of $L L R$. However, the HR-amplitude and-duration is slightly higher in the offspring than the controls.

For abbreviations: see fig 2.

\section{Discussion}

The present data shall be discussed with regard to two aspects. The first is concerned with pathophysiological considerations of LLR in chorea. The second deals with the diagnostic implications.

A major result of our study is the demonstration of absent long-latency reflexes in hand muscles following stimulation of mixed proprioceptive and cutaneous 
$\triangle$ Normal subjects,

Symptomatic Chorea
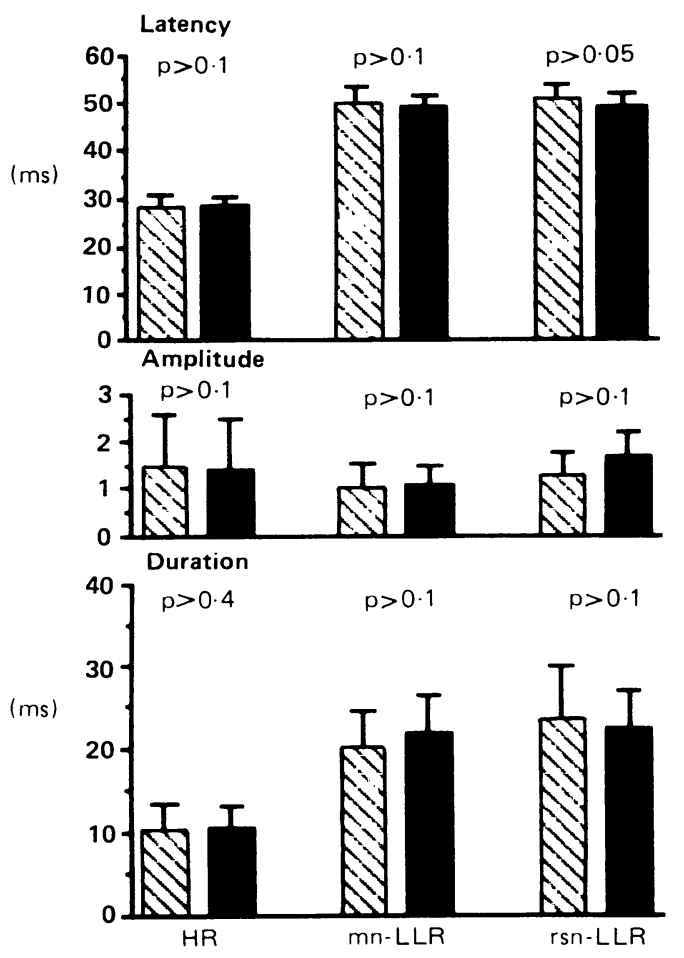

Fig 5 Statistical comparison of reflex parameters of patients with chorea due to various diseases other than $H D$ in $=34$ hands) and age-matched controls. Neither HR-nor LLR-values differed significantly ( unpaired t-test) For abbreviations: see fig 2.

afferents (median nerve) or cutaneous afferents alone (radial superficial nerve). The absence of cutaneomuscular hand muscle-LLR in HD is a new finding, although this was expected from earlier observations in normal subjects and patients with multiple sclerosis; both, the LLR elicited by muscle afferents and those elicited by cutaneous afferents were shown to be mediated by fast conducting afferents. 'They exhibit similar delay or absence in CNS lesions caused by multiple sclerosis." Our observation that both reflex pathways. the muscular and the cutaneous one, are affected to the same extent in HD may further support the idea that both are conducted along the same neuronal circuits. although a definite proof of this hypothesis is still lacking. The decrease of LLR seems to be a slowly progressive electrophysiological finding in HD which is underlined by the loss of LLR in a single patient during a 4 year period and by the demonstration of already decreased mean LLRamplitudes in those HD patients who still exhibit an

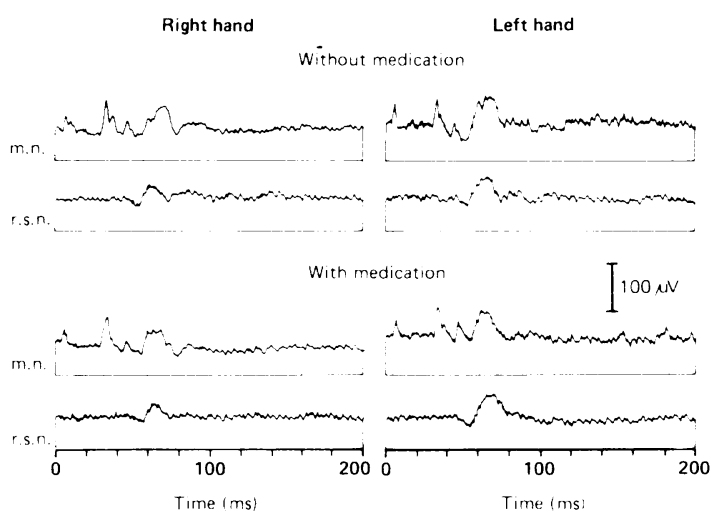

Fig 6 Reflex pattern of a patient with severe estrogeninduced chorea before and after control of her hyperkinesia by $600 \mathrm{mg}$ Tiaprid. No significant differences of the $L L R$ could be found. A small and normal LLR I is discernible between the HR and the LLR (LLRII) following median nerve ( $\mathrm{mn}$ ) stimulation.

LLR. Similarly a progressive decrease of the amplitudes of the somatosensory evoked potentials has been reported. ${ }^{20}$

It has to be considered whether the decrease of LLR-amplitudes could be due to refractoriness of the motoneurons caused by the enlarged HR. It is impossible to exclude such an influence. However, there are two arguments against a major contribution by this factor. Firstly, we also found absent LLR in patients with normal HR-amplitudes. Secondly, the LLR following cutaneous stimulation are absent although they are not preceded by a comparable large reflex. Furthermore, from our experience in normal subjects we have no evidence for a negative correlation between HR-amplitude and LLR-amplitude.

Chorea is a symptom of basal ganglia disorders. The absence of hand-muscle LLR in HD is surprising as the reflex pathway for them is believed to be located within the lemniscal afferent pathway to the cortex and back along the pyramidal tract to the motoneurons. ${ }^{1213}$ An interesting hypothesis to explain this discrepancy has been proposed. ${ }^{15}$ The absent or diminished LLR on one hand and the diminished early components of the somatosensory evoked cortical potentials to median nerve stimulation on the other hand could be explained on a common basis by the following pathophysiological mechanism: It is well know that the amplitude of the cortical SEP-complex decreases during voluntary movements. ${ }^{31}{ }^{33}$ This gating mechanism could take place to the same extent during involuntary movements and thereby explain a reduction of the afferent inflow to the cortex which consequently causes the reduction of SEP amplitudes and the loss of LLR. If so, one would expect that diseases 
associated with severe chorea other than HD, are also accompanied by a reduction of the LLR. The present data argue against this view. Firstly, all patients with symptomatic chorea had preserved LLR. Secondly, we could not detect any reduction of the mean LLR amplitude for the patients with symptomatic chorea compared with controls. Thirdly, the LLR amplitude was reduced even in those patients with HD who still had preserved reflexes but it was normal in the patients with symptomatic aetiologies. On the other hand the mean score of the choreatic movement disorder was higher in the patients with symptomatic aetiologies than in those with HD. Hence, there seems to be no relation between the amount of choreatic hyperkinesia and the LLR amplitude. We conclude from our data that the choreatic hyperkinesia per se does not influence the LLR amplitudes significantly. Moreover, a functional disturbance of the reflex exerted by the disordered basal ganglia outflow seems to be unlikely as we found absent and diminished LLR among the investigated patients with chorea only in the case of HD. Investigations concerning the influence of choreatic hyperkinesia on the amplitude of the early component of the SEP when the patients were awake or asleep could detect only minor effects. ${ }^{34}$ Therefore, we assume that the absence or decrease of LLR is due to a degeneration of CNS neurons located within the reflex pathway for the LLR. Following the idea of a transcortical reflex loop it could be suggested that the well-known loss of neurons within the VPL of the thalamus ${ }^{3536}$ explains a reduced afferent inflow to the cortex and thereby causes the loss of LLR. The degeneration of the cortex ${ }^{35}$ including cortico--cortical connections could be another explanation. Future research is needed to substantiate these speculations.

The second and more unexpected finding was the increase of the HR amplitude in patients with HD. This increase was most pronounced for the patients with manifest HD but also the subjects at risk had a slight increase of the mean HR amplitude at a low level of significance. The HR were within normal limits for the patients with symptomatic chorea. Earlier investigations already emphasised a more frequent occurrence of normally absent HR in the relaxed hand muscles following stimulation of median or ulnar nerves in patients with $\mathrm{HD}^{37-39}$ and even in cases with Sydenham's chorea.$^{40}$ However, during relaxed conditions some motoneurons could temporarily receive subliminal facilitation during choreatic movements and thereby mimic a general alteration of the excitability level. With our method voluntary contraction of thenar muscles is required to elicit HR. During this condition baseline activity, HR and LLR should be facilitated to the same extent by a possible spontaneous hyperactivity. Therefore, a selective facilitation of only one reflex, as a consequence of the hyperkin- esia is unlikely. Moreover, patients with severe symptomatic chorea had no enhancement of the HR amplitude.

This may serve as a further argument against unspecific facilitation of HR in HD. Enhanced HR either reflect a facilitation or a disinhibition of the monosynaptic reflex arc and are mostly associated with lesions of descending tract systems ${ }^{41}$ However, a disturbance within the spinal interneuronal network cannot be excluded. It should be emphasised that our data on HR are in contrast to the results obtained with stretch reflexes in hand muscles and finger flexors, ${ }^{1516}$ which failed to detect an increase in the first component of the stretch reflex. This could be due to general differences between these two early reflexes. There is independent evidence that the early components of stretch reflex and the HR are based on partly different neuronal circuits ${ }^{42}$ which could explain the difference.

Eliciting LLR in hand muscles by electrical stimuli is a rather simple and "low-tech" method which can be applied in any routine laboratory for clinical neurophysiology. Therefore, it seems appropriate to make a few remarks on the value of this method for the diagnosis of HD and the differential diagnosis of choreatic movement disorders. Uni- or bilaterally absent LLR have been found in $61 \%$ of our patients with HD. Therefore the absence of LLR seems to be a hallmark of the disease. Compared with other studies using stretch evoked reflexes ${ }^{15}$ the percentage of absent LLR is lower with our method. This could be due to the different methods of eliciting the reflexes. However, it has to be taken into account that our patients with HD were investigated at an early stage of their disease. All except three were referred to our clinic for the first diagnosis of their disease and had mostly still had moderate symptoms. Up to now the diagnosis of HD is mainly based on the clinical picture and a postive family history. A number of electrophysiological tests like median nerve-SEP, ${ }^{17-20} \mathrm{P} 300{ }^{28}$ EOG ${ }^{29}{ }^{20}$ and neuroimaging techniques like $\mathrm{CT},{ }^{4344}$ $\mathrm{NMR}^{25}$ or especially $\mathrm{PET}^{45}$ may confirm the diagnosis. LLR-testing can be regarded as one of them. Our experience seems to indicate that it is valuable as a part of this series of tests and may help to confirm the diagnosis at an early stage. This can be an important help for the future plans of the patients. Our results in clinically healthy subjects at risk for HD are somewhat disappointing since we failed to find subjects with clearcut abnormalities. A parallel study with stretch evoked reflexes ${ }^{46}$ also found abnormal responses in but a small percentage of patients. Therefore, we conclude that the LLR may be an early symptom of the disease but we have no evidence that it is worthwhile for the identification of presymptomatic gene carriers.

The differential diagnosis of choreatic movement disorders is a rare, but difficult problem in everyday- 
practice. There are many diseases with choreatic hyperkinesias. ${ }^{478} \mathrm{~A}$ considerable number of these are accompanied with psychoorganic alterations. Faced with these difficulties it can be useful to have simple electrophysiological tests that help to confirm the diagnosis of HD. Our result of a normal reflex pattern in all the patients with choreatic disorders other than HD may prove helpful in this. Other reports of single cases with benign hereditary chore ${ }^{49}$ and patients with systemic lupus erythematodes ${ }^{50}$ are in line with our results as they also failed to detect any abnormalities of the reflex pattern. Compared with other choreatic movement disorders absent LLR seem to be a unique finding in HD. Of course it has to be excluded that the loss of LLR is not due to a stroke, ${ }^{6}$ multiple sclerosis ${ }^{6}$ or any other cerebral or spinal lesion that can cause selective abolition of LLR.

Finally, we conclude that the method of eliciting hand-muscle LLR is a valuable auxiliary method for diagnosis and differential diagnosis of HD if critically applied.

We are grateful to Mrs W Vasold for expert technical assistance and Mrs T Ebner for linguistic corrections. This work was supported by the Deutsche Forschungsgemeinschaft (SFB 325).

\section{References}

1 Upton ARM, McComas AJ, Sicca REP. Potentiation of "late" responses evoked in muscles during effort. $J$ Neurol Neurosurg Psychiatry 1971;34:699-711.

2 Milner-Brown HS, Stein RB, Lee RG. Synchronization of human motor units: possible roles of exercise and supraspinal reflexes. Eletroencephalogr Clin Neurophysiol 1975;38:245-54.

3 Deuschl G, Schenck E, Lücking $\mathrm{CH}$. Long-latency responses in human thenar muscles mediated by fast conducting muscle and cutaneous afferents. Neurosci Lett 1985;55:361-6.

4 Deuschl G, Schenck E, Lücking $\mathrm{CH}$, Ebner $\mathrm{A}$. Cortical reflex myoclonus and its relation to normal long-latency reflexes. In: Benecke R, Conrad C, Marsden CD, eds. Movement Disorders I. London: Academic Press, 1987:305-19.

5 Conrad B, Aschoff JC. Effects of voluntary isometric and isotonic activity on late transcortical reflex components in normal subjects and hemiparetic patients. Electroencephalogr Clin Neurophysiol 1977;42:107-16.

6 Deuschl G, Strahl K, Schenck E, Lücking $\mathrm{CH}$. The diagnostic significance of long-latency reflexes in multiple sclerosis. Electroencephalogr Clin Neurophysiol 1988;70:56-61.

7 Caccia MR, McComas AJ, Upton ARM, Blogg T. Cutaneous reflexes in small muscles of the hand. $J$ Neurol Neurosurg Psychiatry 1973;36:960-77.

8 Eisen A, Burton K, Larsen A, Hoirch M, Calne D. A new indirect method for measuring spinal conduction velocity in man. Electroencephalogr Clin Neurophysiol 1984;59:204-13.

9 Jenner JR, Stephens JA. Cutaneous reflex responses and their central nervous pathways studied in man. J Physiol (Lond) 1982;333:405-19.

10 Claus D, Lang C, Kotzian J. Zur Bezeihung zwischen Long-loop Reflexbefund und Topograpie von Hirninfarkten. $Z$ EEGEMG 1985;16:191-5.

11 Deuschl G, Schenck E, Lücking $\mathrm{CH}$. Essential tremor: electro- physiological and pharmacological evidence for a subdivision. J Neurol Neurosurg Psychiatry 1987;50:1435-41.

12 Marsden CD, Rothwell JC, Day BL. Long-latency automatic responses to muscle stretch in man: origin and function. In: Desmedt JE, ed. Advances in Neurology, Motor control Mechanisms in Health and Disease. New York: Raven Press, 1983;50939.

13 Wiesendanger $M$. Experimental evidence for the existence of a proprioceptive transcortical loop. In: Freund HJ, Büttner U, Cohen B, Noth J, eds. Progress in Brain Research, vol 64. Amsterdam: Elsevier, 1986:67-74.

14 Noth J, Friedemann HH, Podoll K, Lange HW. Absence of longlatency reflexes to imposed finger displacements in patients with Huntington's disease. Neurosci Lett 1983;35:97-100.

15 Noth J, Podoll K, Friedemann HH. Long-loop reflexes in small hand muscles studied in normal subjects and in patients with Huntington's disease. Brain 1985;108:65-80.

16 Thompson PD, Berardelli A, Rothwell JC, et al. The coexistence of bradykinesia and chorea in Huntington's disease and its implications for theories of basal ganglia control of movement. Brain 1988;111:223-44.

17 Oepen G, Doerr M, Thoden U. Visual (VEP) and somatosensory (SSEP) evoked potentials in Huntington's chorea. Arch Psychiatr Nervenkr 1981;229:205-13.

18 Bollen EL, Arts JR, Roos RAC, van der Velde EA, Burnma OJS. Somatosensory evoked potentials in Huntington's chorea. Electroencephalogr Clin Neurophysiol 1985;62:235-40.

19 Noth J, Engel E, Friedemann H-H, Lange H. Evoked potentials in patients with Huntington's disease and their offspring. I Somatosensory evoked potentials. Electroencephalogr Clin Neurophysiol 1984;59:34-41.

20 Ehle AL, Stewart RM, Lellelid NA, Leventhal NA. Evoked Potentials in Huntington's disease. A Comparative and Longitudinal Study. Arch Neurol 1984;41:379-82.

21 Deuschl G, Lücking CH, Schenck E. Electrically elicited longlatency reflexes in thenar muscles: abnormal patterns in central movement disorders. J Neurol Suppl 1985;232:255.

22 Matthews PBC. Observations on the automatic compensation of reflex gain on varying the pre-existing level of motor discharge in man. J Physiol (Lond) 1986;374:73-90.

23 Meinck HM, Berkefeld J, Conrad B, Kutaneo-muskuläre Reflexe der menschlichen Hand II. Neurophysiologische Aspekte der Reflex-Organisation und -Koordination. $Z$ EEG-EMG 1987;18:101-7.

24 Wolff G, Deuschl G, Wienker TF, et al. New Mutation to Huntington Disease. J Med Genet 1989;26:18-27

25 Ott D, Schumacher M. Neuroradiologische Diagnostik bei Huntingtonscher Krankheit. In: Deuschl G, Oepen G, Wolff G, eds. Die Huntingtcnsche Krankheit. Heidelberg: Springer, 1988: 118-21.

26 Botsch H, Oepen G, Deuschl G. SPECT-Untersuchungen mit 99m-Tc-HMPAO bei Patienten mit Huntingtonscher Chorea. Fortschr Roöntgenstr 1987;147:666-8.

27 Wallesch CW, Fehrenbach RA. On the neurolinguistic nature of language abnormalities in Huntington's disease. $J$ Neurol Neurosurg Psychiatry 1988;51:367-73.

28 Hömberg V, Hefter H, Granseyer G, Strauss W, Lange H, Hennerici M. Event-related potentials in patients with Huntington's disease and relatives at risk in relation to detailed psychometry. Electroencephalogr Clin Neurophysiol 1986;63: $552-69$.

29 Beenen N, Büttner $U$, Lange $H$. The diagnostic value of eye movement recordings in patients with Huntington's disease and their offspring. Electroencephalogr Clin Neurophysiol 1986;63:119-27.

30 Oepen G, Clarenbach P, Thoden U. Disturbance of eye movements in Huntington's chorea. Arch Psychiatr Nervenkr 1981;229:205-13.

31 Cohen LG, Starr A. Localisation, timing and speciflcity of gaiting of somatosensory evoked potentials during active movements in 
man. Brain 1987:110:451-67.

32 Rushton DN, Rothwell JC, Craggs MD. Gaiting of somatosensory evoked potentials during different kinds of movement in man. Brain 1981;104:465-91.

33 Seyall M, Ortstadt JL, Kraft LW, Gabor AJ. Effect of movement on human spinal and subcortical somatosensory evoked potentials. Neurology 1987;37:650-5.

34 Rodnitzky RL, Yamada T, Ishida T, Walker F. Characteristics of evoked potentials suppression in Huntington's disease. Neurology 1985;Suppl 1;68:5.

35 Roos RAC. Neuropathology of Huntington's chorea. In: Vinken PJ, Bruyn GW, Klawans HL, eds. Handbook of Clin Neurology Vol 49. Amsterdam: Elsevier, 1986:315-26.

36 Lange H, Thörner G, Hopf A, Schröder KF. Morphometric studies of the neuropathological changes in choreatic diseases. $J$ Neurol Sci 1976;28:401-25.

37 Johnson EW, Radecki BV, Paulson GW. Huntington's disease: early identification by H-reflex testing. Arch Phys Med Rehabil 1977;58:162-6.

38 Oepen G, Hillesheimer W. Qualitative H-Reflex testing in Huntington's disease. Arch Psychiatr Nervenkr 1981;230:221-6.

39 Sax DS, Johnson TL, Cooper IJ. Reflex recovery curves in extrapyramidal disorders. In: Eldridge R, Fahn S, eds. Advances in Neurology Vol 14. New York: Raven Press, 1976:285-96.

40 Hodes R, Gribetz I, Hodes L. Abnormal occurrence of the ulnar nerve-hypothenar muscle H-reflex in Sydenham's chorea Pediatrics 1962;30:49-56.

41 Baldissera F, Hultborn H, Illert M. Integration in spinal neuronal Systems. In: Brooks VB, ed. Handbook of Physiology, The Nervous System, Motor control sec 1, vol II. Bethesda, MD American Physiological Society, 1981:505-93.

42 Burke D, Gandevia SC, McKeon B. The afferent volley responsi- ble for spinal proprioceptive reflexes in man. $J$ Physiol (Lond) 1983:535-2.

43 Oepen G, Ostertag C. Diagnostic value of CT in patients with Huntington's chorea and their offspring. $J$ Neurol 1981;225:189-96.

44 Stober T, Wussow W, Schimrigk K (1984) Bicaudate diameterthe most specific and simple CT parameter in the diagnosis of Huntington's disease. Neuroradiology 1985;26:25-8.

45 Young AB, Penney JB, Starosta-Rubenstein S, et al. Normal caudate glucose metabolism in persons at risk for Huntington's disease. Arch Neurol 1987;44:254-7.

46 Noth J, Podoll K. Chorea/Tics:: Clinical aspects and treatment. In: Benecke R, Conrad C, Marsden CD, eds. Movement Disorders I. London: Academic Press, 1987:231-42.

47 Deuschl G, Lücking CH. Die klinische Differentialdiagnose choreatischer Hyperkinesen. In: Deuschl G, Oepen G, Wolff G, eds. Die Huntingtonsche Krankheit. Heidelberg: Springer, 1988:3-11.

48 Padberg GW, Bruyn GW. Chorea-differential diagnosis. In: Vinken PJ, Bruyn GW. Klawans HL, eds. Handbook of Clinical Neurology Vol 5 (49) Extrapyramidal Disorders. Amsterdam: Elsevier, 1986:549-64.

49 Lange H, Aulich A, Hefter H, Hömberg V, Noth J, Strauss W. Benign hereditary chorea. A neuroradiologic, physiologic and psychometric investigation. In: Benecke R, Conrad C, Marsden CD, eds. Movement Disorder I. London: Academic Press, 1987:523-64

50 Guttman M, Lang AE, Garnett ES, Nahmias C, Firman G, Tyndel FJ, Gordon AS. Regional cerebral glucose hypometabolism in SLE chorea: Further evidence that striatal hypometabolism is not a correlate of chorea. Movemen Disorders 1987;2:201-10. 